\title{
Implementing cellular manufacturing in small scale industries
}

\author{
B. N. Shishir Bhat
}

Received: 18 January 2008 / Accepted: 21 April 2008

(C) Springer Science+Business Media, LLC 2009

This article has been retracted due to plagiarism. 